\title{
Genetic and Psychosocial Risk Factors Associated with Suicide Among Community Veterans: Implications for Screening, Treatment and Precision Medicine
}

\author{
Joseph A Boscarino (D) \\ Richard E Adams $\mathbb{D}^{2}$ \\ Thomas G Urosevich ${ }^{3}$ \\ Stuart N Hoffman ${ }^{4}$ \\ $\mathrm{H}$ Lester Kirchner ${ }^{\prime}{ }^{\prime}$ \\ Xin Chu $\mathbb{D D}^{5}$ \\ Weixing $\mathrm{Shi}^{5}$ \\ Joseph J Boscarino ${ }^{6}$ \\ Ryan J Dugan (ID) \\ Carrie A Withey ID $^{\prime}$ \\ Charles R Figley (D) $^{7}$ \\ 'Department Population Health Sciences, \\ Geisinger Clinic, Danville, PA, I7822, USA; \\ ${ }^{2}$ Department Sociology, Kent State \\ University, Kent, $\mathrm{OH}, 44242$, USA; \\ ${ }^{3}$ Ophthalmology Service, Geisinger Clinic, \\ Mount Pocono, PA, I8344, USA; \\ ${ }^{4}$ Department Sleep Medicine, Geisinger \\ Clinic, Danville, PA, 17822, USA; ${ }^{5}$ Obesity \\ Institute, Geisinger Clinic, Danville, PA, \\ 17822, USA; ${ }^{6}$ Department of Neurosurgery \\ and Brain Repair, University of South Florida \\ Morsani College of Medicine, STC 7, Tampa, \\ FL, 33606, USA; ${ }^{7}$ School of Social Work, \\ Tulane University, New Orleans, LA, \\ 70II2, USA
}

\begin{abstract}
Introduction: Since veteran suicide is a concern and our knowledge of predictive factors is still limited, our objective was to assess risk factors for suicide, including genetic factors, among deployed veterans.

Methods: For this study, we surveyed 1730 veterans who were outpatients in a multihospital system in Pennsylvania. Altogether, 1041 veterans (60\%) provided a DNA sample. The genetic risk variants investigated were within loci previously associated with PTSD and substance misuse, including CRHR1, CHRNA5, RORA, and FKBP5 genetic variations, which were used to calculate a polygenic risk score (range $=0-8$, mean $=3.6, \mathrm{SD}=1.4$ ).

Results: Most veterans (56.2\%) were deployed to Vietnam while significant numbers were deployed to Iraq, Afghanistan, and other post-Vietnam conflicts. Overall, $95.1 \%$ of the veterans were male, their mean age was $56.2(\mathrm{SD}=12)$, and $95.6 \%$ were Caucasian. Among the veterans, $24 \%$ had high combat exposure. The prevalence of lifetime suicidal thoughts was $11.3 \%$. Additionally, 5.7\% ever developed a suicide plan or attempted suicide in their lifetimes. Among those with a history of a lifetime suicide attempt or suicide plan, the PTSD genetic risk score was significantly higher ( $\mathrm{OR}=3.96$ vs $3.55, \mathrm{p}=0.033$ ), but for suicidal thoughts, this association was not significant ( $\mathrm{p}=0.717$ ). In multivariable analysis (MVA) logistic regression, significant predictors of attempting suicide or having a suicide plan were history of depression (OR=5.04, $\mathrm{p}<0.001)$, PTSD genetic risk score $(\mathrm{OR}=1.25, \mathrm{p}=0.036)$, history of childhood abuse/neglect $(\mathrm{OR}=2.24, \mathrm{p}=0.009)$, and lifetime marijuana use $(\mathrm{OR}=1.56, \mathrm{p}=0.020)$. Conversely, rural residence was protective for suicide risk ( $\mathrm{OR}=0.49 ; \mathrm{p}=0.031)$. For suicidal thoughts, in the MVA genetic risk score was not significant $(\mathrm{p}=0.697)$, but history of child abuse/neglect $(\mathrm{p}<0.001)$, history of depression $(\mathrm{p}>0.001)$, low psychological resilience $(\mathrm{p}=0.004)$, and lifetime marijuana use $(\mathrm{p}=0.022)$ were significant.

Discussion: In this study, we identified genetic risk variants and other predictors for suicide among veterans that may have implications for future screening and clinical care. Further research is advised.
\end{abstract}

Keywords: veterans, warzone deployment, suicide, genetic factors, patient screening, precision medicine

\section{Introduction}

Research suggests that significant numbers of former service members have developed mental health disorders following deployments. ${ }^{1-5}$ In the current study, we examine the impact of risk and protective factors, including genetic measures, for suicide among veterans. ${ }^{6}$ Consistent with previous research, ${ }^{7}$ the objective of this
Correspondence: Joseph A Boscarino Department Population Health Sciences, Geisinger Clinic, 100 N. Academy Ave., 44-00, Danville, PA, I7822, USA

Tel + I 570-2|4-9825

Email joseph.boscarino@gmail.com 
study is to assess the impact of pre- and post-deployment factors on the mental health status of military veterans.

Given previous research, ${ }^{8}$ our supposition was that veteran suicidality was associated with more prevalent mental health disorders, existing personality factors, negative life events, as well as genetic factors. ${ }^{6,9}$ Recent studies have confirmed that suicidal behavior among veterans is complex and associated with both individual and community-level factors. ${ }^{10-12}$ In addition, some research suggests that veterans may not have a higher risk of suicide than comparable community-based non-veterans. ${ }^{13,14}$ However, a great deal of opposing research suggests otherwise. ${ }^{15}$ Furthermore, suicide risk among veterans is not exclusively limited to deployments or combat exposure, per se, ${ }^{16}$ which emphasizes the importance of identifying other predictive factors. There is growing evidence to date supporting genetic risk factors of suicide among veterans, but research on this topic is insufficient. ${ }^{17-19}$ Consequently, risks for suicide among veterans may have a heritable component that cannot be explained by psychosocial or warzone exposures alone. ${ }^{20,21}$ Updated research is needed to address the aforementioned knowledge gap. To assess this, we employed a genetic prediction model that we used successfully in past research among both veterans and nonveterans. ${ }^{6,9,22,23}$

Our assessment includes veterans from different conflicts, which may better represent the "real-world" population of current veterans. ${ }^{5,24}$ As we note below, our analysis includes veterans that both do and do not use the VA health system. ${ }^{7}$ Understanding deployment-related risk factors among veterans is imperative for more effective prevention and treatment of mental health disorders among the veteran population. ${ }^{25}$ In addition, we would expect that veterans would have both risk and protective factors related to suicide, including level of support, service history, personality factors among others. ${ }^{26-29}$ This knowledge is also important for both VA and non-VA providers, since recent policy changes in the US have expanded access to health care for veterans outside of the VA healthcare system. ${ }^{30,31}$ This service trend is also observed among service members worldwide. ${ }^{24,32}$

Our primary hypothesis is that a genetic association would be found for suicidal behaviors (ie, planning and attempting suicide) but not for suicidal thoughts, which is more nebulous and subjective, compared to behaviors. ${ }^{17,33}$ While the genetic bases for suicide are still unclear, the links between PTSD, suicide, and mental health status among veterans is more unambiguous. ${ }^{8,34}$ This is especially true as it relates to the onset of "complex" PTSD following high combat and high trauma exposures. ${ }^{35}$ In fact, the PTSD D4 criteria in DSM-5 specifically stipulates that one of the characteristic symptoms for PTSD is the onset of a persistent negative emotional state, including fear, horror, anger, guilt, and shame, ${ }^{36}$ which could result in self-harm risk over time. Our secondary hypothesis is that heavy marijuana use would be associated with suicide, which is a concern among veterans and other groups. ${ }^{37}$ Our tertiary hypothesis is that rural veterans would be at a lower risk of suicidal behaviors. ${ }^{24}$

Noteworthy, however, is that our study is a prediction of suicide among deployed veterans, so our focus is on predictions among warfighters, and the most relevant exposures for them are typically combat exposure and deployment history. As discussed below, for combat exposure we used the Combat Experience Scale, a measure used in veteran studies for decades. ${ }^{34}$ We also measured Adverse Childhood Experiences (ACE) using the ACE scale and a lifetime trauma exposure scale also widely used in trauma research. ${ }^{38-40}$ Finally, our research was directed by the "Stress Process Model," which focuses on psychosocial support and risk factors that occur in the pre-trauma, trauma, and post-trauma periods and this guided our variable selection and analyses. ${ }^{40-42}$

\section{Methods}

\section{Sample}

The population for the current study included a sample of US military veterans recruited for a study of the health effects of military service. ${ }^{6,40}$ All veterans in the study were outpatients in the Geisinger Clinic, the largest multihospital system in central Pennsylvania. ${ }^{7}$ In 2007, Geisinger initiated a veterans' registry for patients receiving outpatient care. Over 35,000 patients have provided this information, and this was used to select a random sample of veterans for the current study. Geisinger is an integrated health services organization. This system serves more than 3 million residents throughout 45 counties in central, south-central, and northeast Pennsylvania and encompasses a 40,000 square kilometer $(25,000$ square mile) service area (see: www.geisinger.org). The Geisinger system includes more than 30,000 employees, 1600 employed physicians, 10 hospital campuses, a 551,000-member managed care plan, a medical school, and is an open healthcare system that accepts all insurance and payer types, including private consumers and public insurance (Medicare, Medicaid), Tricare, as well as payments for VA care. 
Following patient consent, interviewers administered structured diagnostic health interviews by telephone from February 2016 through February 2017. All veterans recruited for the current study had one or more warzone deployments. Veteran status and deployment history were confirmed based on military records. Among the veterans identified for the surveys, all were under 76 years old and served in Vietnam or a post-Vietnam conflict (ie, Iraq, Afghanistan, Persian Gulf, or other recent conflict). After a total of 10 telephone calls, we were able to complete interviews with $55 \%$ of eligible veterans $(\mathrm{N}=1730){ }^{7}$ Using demographic data in the electronic medical record, the only significant differences found between survey responders and non-responders were that responders tended to be younger and more often married. ${ }^{7}$ Among those surveyed, $60 \%$ veterans provided DNA by mail after several follow-up attempts $(n=1074)$. When asked why the veteran returned the DNA, they reported they did this for "self-knowledge/benefit" and to help other veterans. ${ }^{43}$ Oragene DNA saliva kits, manufactured by Genotek (Ottawa, Ontario, Canada), were used to collect DNA following the manufactures' instructions. To avoid confounded results due to genetic admixture, ${ }^{44}$ nonCaucasian veterans $(n=40)$ were excluded from the generic analyses, resulting in a final study sample of 1041 veterans. $^{6}$

\section{Measures}

To assess suicide, we used measures from the Clinical International Diagnostic Interview (CIDI). ${ }^{45}$ The CIDI instrument is a commonly used diagnostic survey now used worldwide. ${ }^{46,47}$ For the CIDI, we included measures related to suicidal thoughts and suicidal-related behaviors, including having suicide plans and past suicide attempts. ${ }^{45,48,49}$ Given the number of potential predictor variables assessed, we based our analyses on previous conceptual models and empirical results and selected variables that reflected key demographics, military, stressful event, and personality factors pre-, during, and post-trauma exposure and identified as the "stress process model.",6,50

To assess PTSD, we used an instrument based on the Diagnostic and Statistical Manual of Mental Disorder, Fifth Edition (DSM-5), the PTSD Checklist for DSM-5. ${ }^{51,52}$ To receive a diagnosis of PTSD, veterans had to meet the DSM5 diagnostic criteria A through G. ${ }^{36}$ This PTSD scale has been used in recent studies ${ }^{40,53,54}$ and is reported to be a valid and reliable scale ${ }^{6}$ (Cronbach Alpha $=0.92$ ). Nearly $80 \%$ of the veterans in the current study reported that the most significant lifetime stressor they experienced was warzone exposure. ${ }^{7}$ In addition to PTSD, the survey collected data related to the veteran's military history, combat exposure, mental health status, and demographic factors. ${ }^{6,40}$

Depression was assessed using a major depressive disorder scale based on the DSM-IV diagnostic criteria, ${ }^{55,56}$ which has been used in previous studies. ${ }^{5,57-59}$ Data related to the validity of this depression scale were previously reported and suggest that this scale can be used to diagnose depression in community-based population studies. ${ }^{60}$ (Cronbach Alpha $\left.=0.90\right)$. To meet criteria in the study, subjects had to meet the full diagnostic criteria for lifetime major depressive disorder. ${ }^{55,56}$

Other variables in the study included demographic and military factors (eg, age, gender, race, rural residence, warzone deployments, and combat exposure), which were derived from the survey instrument or US Census data, as in the case of rural residence, and used in previous studies. ${ }^{5,24,50}$ Warzone exposures included the Vietnam War, Persian Gulf War, Afghanistan/Iraq War, and "other" recent warzone deployments, as defined by the VA. Global War on Terrorism (GWOT) veterans $(\mathrm{n} \sim 50)$ were combined with Iraq/Afghanistan veterans, since these deployments were during the same timeframe and were in supporting theaters of operations. Combat exposure was based on the Combat Experience Scale and versions of this scale have been used in studies since before the Vietnam $\mathrm{War}^{61-64}$ (Cronbach Alpha $=0.81$ ). Based on previous research, scale measures for combat exposure were divided into standard cut-points based on quartiles and described elsewhere. ${ }^{7,50}$

Our study also assessed the occurrence of lifetime traumatic events using a traumatic event scale (eg, forced sexual contact, domestic abuse, a serious accident, served in a warzone, experienced a disaster, etc.) used in previous research. ${ }^{58,65}$ As we had no measure to judge the severity of these events in our survey, we collapsed these into three categories: less than 3 traumatic events, 3-5 events, and 6 or more events, as has been done in other traumatic stress disorder studies. ${ }^{6,24,25,40,59,66,67}$ A total of $21 \%$ of respondents experienced 6 or more lifetime traumatic events in the current study and we used this to define "high" lifetime traumatic event exposure. ${ }^{68}$ This traumatic event scale was developed from other trauma studies, was used in previous research, and has demonstrated good reliability and validity. ${ }^{58,59,65}$ Psychological resilience was assessed by an instrument used and validated in previous research, the Connor-Davidson Resilience Scale (CD-RISC) ${ }^{69}$ The Cronbach alpha for this scale in the current study was 0.80 
and the scale was coded as high vs not high based on the highest quartile. $^{5}$

Marijuana use was based on survey questions that have been used in previous trauma research to measure marijuana use.$^{60,67}$ In the current study, this scale was used as an ordinal variable (coded as: never used, used occasionally but less than 50 times, and used 50 or more times). Approximately $10 \%$ of veterans reported using marijuana 50 or more times. Rural residence was based on ZIP Code Tabulation Areas (ZCTAs) developed by the United States Census Bureau. These were introduced with the 2000 Census to improve land area classifications. ${ }^{24}$ For the current study, we defined "rural" as an area in which $95 \%$ of the households were in a rural land area, which represented $46 \%$ in the households in the current study.

We note that the current study is primarily a diagnostic study that used diagnostic instruments and scales based on the Diagnostic and Statistical Manual (DSM) criteria for PTSD and depression. ${ }^{36}$ The study also collected DNA and data from the veteran's electronic medical records. This study (funded by the US Department of Defense) collected detailed data on combat exposures, from the military record, reported homecomings experiences, and other military incidents. ${ }^{6}$ The DSM does collect symptom data, but these are used to qualify for the diagnostic criteria, including to define the onset and course of disorders. ${ }^{70}$ Most contemporary epidemiological studies use DSM instruments to collect population-based mental health diagnostic data. ${ }^{46,47,71}$

Based on previous studies, we also used a genetic risk score approach, which included 4 SNP candidate gene variants. $^{22}$ These SNP markers were combined into a cumulative risk allele count, as is common in genetic analyses. ${ }^{6,44}$ For the current study, we assessed 4 genetic markers using a cumulative risk-allele model to test for an association with PTSD among outpatients, comparable to what has been undertaken to predict genetic associations in other clinical areas. ${ }^{72}$ Extending previous research, ${ }^{22}$ we specifically genotyped SNPs located within the FK506 binding protein-5 (FKBP5), retinoid-related orphan receptor alpha $(R O R A)$, cholinergic receptor nicotinic alpha-5 (CHRNA5), and the corticotropin-releasing hormone receptor-1 (CRHR1) gene clusters and assessed these markers for cumulative risk for suicide.

The RORA genetic marker examined (rs8042149) is associated with PTSD in recent research. ${ }^{73}$ The FKBP5 genetic marker studied (rs9470080) regulates glucocorticoid receptor sensitivity, is functionally involved in the hypothalamic-pituitary-adrenal (HPA) stress axis, known to be involved in psychological stress and associated with PTSD. $^{74,75}$ The CHRNA5 genetic marker investigated (rs16969968), which encodes components of the nicotinic acetylcholine receptor (nAChR), is associated with nicotine dependence and cigarette smoking, ${ }^{76}$ substance misuse, ${ }^{77}$ and PTSD. ${ }^{23}$ The CRHR1 genetic marker studied (rs110402) is a polypeptide hormone and neurotransmitter involved in corticotropin-releasing hormone activity associated with the stress response. Studies suggest that this gene also regulates HPA axis function and is associated with the impact of traumatic stress exposure and PTSD. $^{78}$

The risk alleles were counted for each of the 4 genetic variants included, which resulted in a genetic risk score ranging from 0 to 8 , using the risk alleles variants $(A, G, T$, respectively). This genetic risk method has been described in detail elsewhere. ${ }^{6}$ Assessment of these 4 PTSD genetic markers indicated that all were positively associated with PTSD, with two markers (RORA and FKBP5) significantly associated (both $\mathrm{p}$-values $<0.05$ ). In addition, the cumulative unadjusted genetic risk score was also significantly associated with PTSD diagnosis $(\mathrm{p}$-value $=0.033$ ). This genetic risk score was then used as a covariate in our statistical analyses using standard bivariate and multivariate tests. ${ }^{22}$ Risk alleles counted for each of the 4 genetic variants included $0,1,2$ risk alleles, resulting in a genetic risk score ranging from $0-8$ (mean $=3.56$, $\mathrm{SD}=1.41)$, using the risk alleles variants $(\mathrm{A}, \mathrm{G}, \mathrm{T}$, respectively). The rationale for including these genetic markers in our current study was that these were predictive of PTSD among a trauma-exposed populations in past studies, $6,7,22$ and that suicidal behavior was known to be associated with a history of PTSD. ${ }^{7,13,17,22}$ Thus, we hypothesized that this genetic risk score should predict suicidal behaviors and other health outcomes among traumatized populations. ${ }^{79,80}$

\section{Data Analyses}

Statistical analyses included descriptive statistics depicting the study population and testing the associations between mental health, stress exposures, genetic risks, and suicide. For descriptive purposes, we present the characteristics of the total population $(\mathrm{N}=1730)$ and show these results in Table 1. In Table 2, we present the bivariate results for the key risk/protective factors for suicidal behavior and suicidal thoughts for the veterans who provided DNA in the current study $(\mathrm{n}=1041)$. To examine these predictor variables in multivariate analyses, we first used stepwise backwards logistic regression, ${ }^{81}$ and compared these results to 
Table I Profile of Veterans in Veterans' Study Total Sample $(\mathrm{N}=1730)$

\begin{tabular}{|c|c|c|c|}
\hline Variables or mean & (N) & $\%$ & (95\% C. I.) \\
\hline \multicolumn{4}{|l|}{ Age $($ Mean $=59.6 . S D=12.8)$} \\
\hline $18-39$ & $(177)$ & 10.2 & $8.9-11.8$ \\
\hline $40-64$ & $(574)$ & 33.2 & $31.0-35.4$ \\
\hline 65 or older & $(979)$ & 56.6 & $54.2-58.9$ \\
\hline \multicolumn{4}{|l|}{ Sex } \\
\hline Female & $(85)$ & 4.9 & $4.0-6.0$ \\
\hline Male & $(1645)$ & 95.1 & $94.0-96.0$ \\
\hline \multicolumn{4}{|l|}{ Race } \\
\hline Non-White & $(75)$ & 4.3 & $3.5-5.4$ \\
\hline White & $(1655)$ & 95.7 & $94.6-96.0$ \\
\hline \multicolumn{4}{|l|}{ Marital Status } \\
\hline Married & $(1340)$ & 77.5 & $75.4-79.4$ \\
\hline Not Married & $(390)$ & 22.5 & $20.6-24.6$ \\
\hline \multicolumn{4}{|l|}{ Deployed as Guard/Reserve } \\
\hline No & (1322) & 76.4 & $74.4-78.4$ \\
\hline Yes & $(408)$ & 23.6 & $21.6-25.6$ \\
\hline \multicolumn{4}{|l|}{ Multiple Warzone Tours } \\
\hline No & $(104 I)$ & 60.3 & $58.0-62.6$ \\
\hline Yes & $(686)$ & 39.7 & $37.4-42.1$ \\
\hline \multicolumn{4}{|l|}{ Warzone* } \\
\hline Vietnam & $(972)$ & 56.2 & $53.8-58.5$ \\
\hline Persian Gulf & $(275)$ & 15.9 & $14.3-17.7$ \\
\hline Iraq/Afghanistan/GWOT & $(396)$ & 22.9 & $21.0-24.9$ \\
\hline Other Post-Vietnam Conflict & $(245)$ & 14.2 & $12.6-15.9$ \\
\hline \multicolumn{4}{|l|}{ Service Branch* } \\
\hline Air Force & $(288)$ & 16.7 & $15.0-18.5$ \\
\hline Army & $(861)$ & 49.8 & $47.4-52.1$ \\
\hline Navy & (374) & 21.6 & $19.7-23.6$ \\
\hline Marines & $(194)$ & 11.2 & $9.8-12.8$ \\
\hline \multicolumn{4}{|l|}{ VA Services Use* } \\
\hline Ever used VA & $(1073)$ & 62.0 & $59.7-64.3$ \\
\hline Currently use VA & $(864)$ & 49.9 & $47.6-52.3$ \\
\hline \multicolumn{4}{|l|}{ Suicide } \\
\hline Ever Thoughts & $(196)$ & 11.3 & $9.9-12.9$ \\
\hline Ever Thought Seriously about Suicide & (209) & 12.1 & $10.6-13.7$ \\
\hline Ever Plan or Attempt Suicide & $(98)$ & 5.7 & $4.6-6.9$ \\
\hline Suicide Thoughts in Past Month & (94) & 5.5 & $4.4-6.6$ \\
\hline
\end{tabular}

Note: *Multiple responses allowed.

Abbreviation: GWOT, Global War on Terrorism.

the stress process conceptual model to select candidate variables. ${ }^{7}$ Consequently, key risk/protective factors (eg, lifetime trauma exposure, number of deployments, other mental disorders, and demographic factors) were used to estimate the likelihoods (ie, odds ratios, ORs) for suicidal behaviors/thoughts by including these variables in multivariable analysis (MVA) regressions (Tables 3 and 4). All the variables shown in the final multivariate models are included in the analyses presented. We separately assessed suicidal behaviors (eg, ever had a suicide plan or attempted suicide) and suicidal ideation (eg, ever had suicidal thoughts for two weeks or more). We note that for Tables 3 and 4, the sample size is reduced due to the exclusion of non-whites and those missing DNA ( $n=1041)$. Our hypothesis was that suicidal behaviors (eg, suicide attempts and planning) would be associated with genetic risk, but that suicidal thoughts would not be associated with these risk alleles. ${ }^{21}$ We also expected that high trauma exposures and lifetime marijuana use would be associated with suicide. However, these analyses also included lifetime depression disorder, a major risk factor for suicide, so the final regression results were not clear beforehand. In the discussion section of the paper, we review study results as they relate to screening and care for veterans. As a check of our prediction model, we also assessed suicidal thoughts in the past 30 days and report these results in the results section. Statistical analyses were conducted using Stata, version 15.1 and SPSS, version 20 software.

\section{Institutional Review Board Approval}

This study was approved by the Institutional Review Boards of the Geisinger Clinic (IRB \# 2015-0441) and the US Department of Defense (IRB \# A-18989). All patients provided their informed consent to participate in the study and were offered small monetary incentives for participation. The study data were also protected by a Certificate of Confidentiality $(\mathrm{CoC})$ issued by the National Institutes of Health (NIH). This study was conducted in accordance with the principles stated in the Helsinki Declaration.

\section{Results}

Most veterans surveyed were over 65 years old (56.6\%), male (95.1\%), Caucasian (95.7\%), and married (77.5\%). In addition, $56.2 \%$ were Vietnam veterans, $49.8 \%$ serviced in the US Army and $39.7 \%$ served on multiple deployments (Table 1). Furthermore, 49.9\% reported using the VA system in the past 12 months. Additionally, $11.3 \%$ had a history of suicidal thoughts, $12.1 \%$ ever thought seriously about suicide, and 5.7\% reported ever having a suicide plan or ever attempting suicide in the past. Finally, 5.5\% of veterans had suicidal thoughts in the past 30 days (Table 1). In terms of other potential mental health risk factors for suicide, among those who completed the survey and provided DNA, the prevalence of lifetime depression was $21.7 \%$ and lifetime PTSD was $12.2 \%$. 
Table 2 Bivariate Associations for Ever Suicide Attempt/Plan Among Community Veterans (N=1073)

\begin{tabular}{|c|c|c|c|c|c|c|}
\hline \multirow[t]{2}{*}{ Study Variables* } & \multirow[t]{2}{*}{ (N) } & \multirow[t]{2}{*}{$\%$ Total } & \multicolumn{2}{|c|}{ Ever Attempt/Plan } & \multirow[t]{2}{*}{ OR } & \multirow[t]{2}{*}{ p-value } \\
\hline & & & $\%$ No & $\%$ Yes & & \\
\hline Mean PTSD Risk Score $\nmid$ & $(104 I)$ & 100.0 & 3.6 & 4.0 & 1.23 & 0.034 \\
\hline$\%$ Age: $65+$ vs $<65$ & $(686)$ & 64.0 & 95.9 & 4.1 & 0.54 & 0.027 \\
\hline$\%$ Female vs Male & $(49)$ & 4.6 & 93.9 & 6.1 & 1.19 & 0.771 \\
\hline \% Iraq/Afghanistan Veteran vs not & $(208)$ & 19.4 & 91.4 & 8.6 & 2.06 & 0.015 \\
\hline$\%$ High Combat Exposure vs not High & $(232)$ & 21.6 & 91.8 & 8.2 & 1.94 & 0.024 \\
\hline \% Child Neglect High vs not High & $(184)$ & 17.1 & 94.8 & 5.2 & 4.02 & $<0.001$ \\
\hline \% High Lifetime Trauma vs not High & $(200)$ & 18.7 & 94.8 & 5.2 & 3.05 & $<0.001$ \\
\hline \% Ever Major Depress. Disorder vs not & $(233)$ & 21.7 & 94.8 & 5.2 & 9.73 & $<0.001$ \\
\hline \% Ever PTSD vs no PTSD & $(|3|)$ & 12.2 & 94.8 & 5.2 & 6.38 & $<0.001$ \\
\hline$\%$ Ever Marijuana $50+$ Times vs not & $(103)$ & 9.6 & 87.4 & 12.6 & 3.11 & 0.001 \\
\hline \% Low Psychological Resilience vs not & $(265)$ & 24.7 & 89.4 & 10.6 & 3.29 & $<0.001$ \\
\hline \% Rural vs Nonrural Residence & $(496)$ & 46.2 & 96.8 & 3.2 & 0.45 & 0.008 \\
\hline Total Column \% & - & - & 94.6 & 5.4 & - & - \\
\hline
\end{tabular}

Notes: *For brevity, we only present the indicator variable results for crosstabulations shown in Table 2. †For genetic analyses, sample was reduced due to missing DNA and exclusion of 40 non-Caucasians.

Table 3 Multivariable Logistic Regression Predicting Ever Suicide Plan or Attempt Among Community Veterans with Genetic Data $(\mathrm{N}=104 \mathrm{I}) \dagger$

\begin{tabular}{|c|c|c|c|c|}
\hline Variables* & OR & z Score & (95\% C.I.) & p-value \\
\hline PTSD genetic risk score & 1.25 & 2.10 & $\mathrm{I} .0 \mathrm{I}-\mathrm{I} .54$ & 0.036 \\
\hline Age (in years) & 0.99 & -0.97 & $0.96-1.01$ & 0.332 \\
\hline Female sex (vs male) & 0.38 & -1.29 & $0.09-1.65$ & 0.195 \\
\hline Married (vs not married) & 0.73 & -0.90 & $0.37-1.45$ & 0.368 \\
\hline High trauma exposure (vs low trauma) & 1.49 & 1.20 & $0.78-2.83$ & 0.228 \\
\hline High combat exposure (vs low combat) & 1.27 & 0.70 & $0.64-2.52$ & 0.487 \\
\hline History of child abuse/neglect (vs none) & 2.34 & 2.60 & $1.23-4.43$ & 0.009 \\
\hline Multiple tours/deployments (vs one) & 0.63 & -1.39 & $0.33-1.21$ & 0.164 \\
\hline Ever major depression (vs no depression) & 5.04 & 4.46 & $2.48-10.27$ & $<0.001$ \\
\hline Ever PTSD (vs no PTSD) & 1.62 & 1.29 & $0.79-3.39$ & 0.195 \\
\hline Low psychological resilience (vs not low) & 1.41 & 1.05 & $0.74-2.69$ & 0.292 \\
\hline Number times ever used marijuanat† & 1.56 & 2.33 & $1.07-2.27$ & 0.020 \\
\hline Rural residence (vs non-rural) & 0.49 & -2.16 & $0.26-0.94$ & 0.031 \\
\hline
\end{tabular}

Notes: *Area under ROC curve $=0.844$, Hosmer-Lemeshow $\chi^{2}=10.37, p=0.240$. †For genetic analyses, sample was reduced due to missing DNA and exclusion of 40 non-Caucasians. †† For MVA logistic regression marijuana use was coded as an ordinal variable coded as: never used, used occasionally, but less than 50 times, and used 50 or more times.

Furthermore, the prevalence of high combat exposure (21.6\%), high lifetime child abuse/neglect $(17,1 \%)$, high lifetime trauma exposure (18.7\%), low psychological resilience $(25.4 \%)$, and the prevalence of lifetime marijuana use more than 50 times $(9.6 \%)$ were noteworthy among the veterans, with all these risk factors associated with increased likelihood of suicidal behaviors (Table 2).

In multivariable analyses among those included in the polygenic analyses $(n=1041)$, significant predictors of having had a suicide plan or attempting suicide were PTSD 
Table 4 Multivariable Logistic Regression Predicting Ever Suicidal Thoughts for Two Weeks or More Among Community Veterans with Genetic Data $(\mathrm{N}=104 \mathrm{I}) \dagger$

\begin{tabular}{|c|c|c|c|c|}
\hline Variables* & OR & z Score & (95\% C.I.) & p-value \\
\hline PTSD genetic risk score & 0.98 & -0.30 & $0.84-1.14$ & 0.761 \\
\hline Age (in years) & 0.99 & -1.46 & $0.97-1.00$ & 0.145 \\
\hline Female sex (vs male) & 1.67 & 1.11 & $0.68-4.09$ & 0.267 \\
\hline Married (vs not married) & 1.50 & $\mathrm{I} .44$ & $0.86-2.59$ & 0.151 \\
\hline High trauma exposure (vs low trauma) & I.II & 0.40 & $0.67-1.81$ & 0.691 \\
\hline High combat exposure (vs low combat) & 1.19 & 0.65 & $0.71-1.98$ & 0.513 \\
\hline History of child abuse/neglect (vs none) & 2.42 & 3.58 & $1.49-3.93$ & $<0.001$ \\
\hline Multiple tours/deployments (vs one) & 0.87 & -0.59 & $0.55-1.38$ & 0.557 \\
\hline Ever major depression (vs no depression) & 10.51 & 9.48 & $6.46-17.10$ & $<0.001$ \\
\hline Ever PTSD (vs no PTSD) & 0.94 & -0.21 & $0.54-1.63$ & 0.835 \\
\hline Low psychological resilience (vs not low) & 1.97 & 2.91 & $1.25-3.11$ & 0.004 \\
\hline Number times ever used marijuanat† & 1.40 & 2.22 & $1.04-1.89$ & 0.026 \\
\hline Rural residence (vs non-rural) & 0.97 & -0.15 & $0.63-1.50$ & 0.883 \\
\hline
\end{tabular}

Notes: *Area under ROC curve $=0.859$, Hosmer-Lemeshow $\chi^{2}=4.95, p=0.763$. $\nmid$ For genetic analyses, sample was reduced due to missing DNA and exclusion of 40 nonCaucasians. $\dagger+$ For MVA logistic regression marijuana use was coded as an ordinal variable: never used, used occasionally, but less than 50 times, and used 50 or more times.

genetic risk score $(\mathrm{p}=0.036)$, lifetime major depression $(\mathrm{p}<0.001)$, history of childhood abuse/neglect $(\mathrm{p}=0.009)$, lifetime marijuana use $(\mathrm{p}=0.020)$ and rural residence, which was protective $(\mathrm{OR}=0.49, \mathrm{p}=0.031)$ (Table 3$)$. For ever having suicidal thoughts, significant predictors were lifetime major depression $(\mathrm{p}<0.001)$, low psychological resilience $\quad(\mathrm{p}=0.004)$, high childhood abuse/neglect $(\mathrm{p}<0.001)$, and lifetime marijuana use $(\mathrm{p}=0.026)$ (Table 4). For having suicidal thoughts in the past 30 days, significant predictors were history of major depression $(\mathrm{p}=0.002)$, history of PTSD $(\mathrm{p}=0.006)$, low psychosocial resilience $(\mathrm{p}<0.001)$, and history of high childhood abuse/neglect $(\mathrm{p}<0.001)$. As with lifetime suicidal thoughts, as hypothesized, current suicidal thought was not associated with the genetic risk score (detailed results available from the senior author [JAB] upon request). Finally, since interaction effects were previously reported for PTSD by trauma exposures, ${ }^{6}$ we also assessed these interaction effects for our suicide measures, but these were not statistically significant.

\section{Discussion}

Consistent with the psychosocial stress process model, ${ }^{40,82}$ our hypothesis was that suicidal behaviors among veterans would be associated with existing mental health disorders and psychosocial factors, independent of warzone experiences. ${ }^{6}$ Recent studies have confirmed that suicidal behavior among veterans is multi-faceted and associated with both individual and societal-level factors. ${ }^{10-12}$
Nevertheless, the influence of genetic factors cannot be ruled out. $^{20,21}$ In summary, we found both risk and protective factors for suicide among a multi-generational cohort of community veterans, including genetic risk factors. Contrary to some reports, however, our study revealed that combat exposure and deployment history were not risk factors for suicide, but that history of childhood neglect/abuse was, as was history of depression, and lifetime marijuana use.

The current study has several strengths. First, we recruited a large sample of community veterans. Second, we used validated scales and survey measures from previous research. ${ }^{7,45,49}$ Third, we included veterans from Vietnam through to current conflicts in Iraq and Afghanistan, something not typically done in veteran studies, but potentially more representative of current community veterans. ${ }^{5}$ Fourth, we examined the relationship between a genetic risk model and several postdeployment mental health predictors including PTSD, depression, history of childhood abuse/neglect, psychological resilience, and lifetime marijuana use.

However, our study has several limitations, including that it was based on a cross-sectional survey. Because of this limitation, it is possible that some associations found in could be reversed, ${ }^{83}$ such that those with post-deployment mental health symptoms may have a more negative recall of different symptoms and other health-related factors. In addition, although our study was based on a large survey, it was conducted among mostly Caucasian patients in a multi- 
hospital system located in central and northeastern Pennsylvania. Furthermore, we found some survey participation differences, whereby survey respondents tended to be younger and more often married (both p-values $<0.05$ ), compared to nonrespondents. ${ }^{5}$

Thus, it may not be possible to generalize these findings to other geographic areas and study populations. As noted elsewhere, however, there are few robust national samples of veterans available for research, since this population tends to be dynamic, given multiple deployments, ongoing conflicts, VA policy changes, the fluctuation in service use, and the aging veteran population. ${ }^{7,84-86}$ In addition, most veterans do not consistently use the VA system for health care, ${ }^{5,87}$ which complicates using samples of veterans for population health research. $^{88}$ Nevertheless, while there were significant differences found between the veterans, as reported elsewhere, there were fewer differences detected in the final adjusted multivariable analyses. $^{7,25}$ In part, this was likely because of the relatively small number of veterans who reported suicidal behaviors (ie, suicide attempts or suicide plans), which were combined into a single category due to their low numbers, potentially biasing our results. This may have limited our ability to detect at statistically significant difference. ${ }^{83}$ In any case, as shown in Table 3, the impact of our genetic score in the study was limited (z-score $=2.10$, compared to major depression $(\mathrm{z}$-score $=4.46)$, likely due to our limited study sample.

\section{Conclusion}

Despite these limitations, our findings are consistent with recent studies, in which researchers reported that service members' pre-deployment, deployment, and post-deployment experiences have an impact on mental health status years afterwards. ${ }^{25}$ We emphasize that services for returning veterans that target modifiable risk factors are important. ${ }^{7}$ Yet, there are currently few specific behavioral health models to improve the homecoming experiences for veterans. ${ }^{89}$ Although recent progress has been made, the reasons why some veterans are at greater risk for suicide are still unclear. For example, the finding that history of marijuana use is associated with suicide among veterans is worthy of further investigation, especially given the legalization of this drug in the US and its experimental use with PTSD-positive veterans. ${ }^{29}$ Following deployments, most veterans return to their local communities and are typically seen in non-government healthcare facilities at least some of the time, ${ }^{90,91}$ potentially complicating their care.

Therefore, providers in non-VA settings need to be aware of the unique clinical presentations and risk factors for these patients. $^{92}$ As noted, one challenge is that there are few representative samples of community veterans to evaluate long-term health outcomes, and the samples that are available are often limited to the VA system. ${ }^{93,94}$ It is well known that hospital and clinic-based sample tend to be biased. ${ }^{95}$ Thus, more broad-based registries for veterans are encouraged, such as those that have been developed in other clinical areas, ${ }^{96}$ especially if this registry can include surveys, electronic health records, and clinical data. ${ }^{97,98}$ Replicating earlier research with non-veterans, ${ }^{9,22,99}$ in the current study we predicted suicidal behaviors among veterans. We previously noted that when genetic information was added to a PTSD risk score it helped improve the accuracy of prediction results for a psychosocial screening instrument that already had good prediction results. ${ }^{9}$ This improvement was achieved by increasing prediction specificity, which may have implications for better precision medicine in the future. Further research is clearly advised since both the phenotypes and genotypes investigated were limited. The polygenic risk score was significant as hypothesized and consistent with previous studies, but additional research is required as this relates to longitudinal research and inclusion of additional phenotypes/genotypes, which is planned in the future.

\section{Acknowledgment}

The study team acknowledges the efforts of the 1730 veterans who took part in this study.

A version of this paper was presented at annual meeting of the Health Care Systems Research Network Virtual Conference, May 11-12, 2021.

\section{Funding}

Funding was provided by: Geisinger Auxiliary Fund, the Kline \& Ditty Health Fund (\#752109 \& \#762170), National Institute of Mental Health (Grant No. R21-MH -086317), Wounded Warrior Project, and the Department of Defense (Contract No. W81XWH-15-1-0506) to J.A. Boscarino. The sponsors had no role in the analysis, writing, or submission of the manuscript.

\section{Disclosure}

The authors declare no conflicts of interests related to this research.

\section{References}

1. Hoge CW, Castro CA, Messer SC, McGurk D, Cotting DI, Koffman RL. Combat duty in Iraq and Afghanistan, mental health problems, and barriers to care. N Engl J Med. 2004;351:13-22. doi:10.1056/NEJMoa040603 
2. Booth-Kewley S, Larson GE, Highfill-McRoy RM, Garland CF, Gaskin TA. Correlates of posttraumatic stress disorder symptoms in Marines back from war. J Traumatic Stress. 2010;23:69-77. doi: $10.1002 /$ jts. 20485

3. Kok BC, Herrell RK, Thomas JL, Hoge CW. Posttraumatic stress disorder associated with combat service in Iraq or Afghanistan: reconciling prevalence differences between studies. J Nerv Ment Dis. 2012;200:444-450. doi:10.1097/NMD.0b013e3182532312

4. Jacobson IG, Ryan MA, Hooper TI, et al. Alcohol use and alcohol-related problems before and after military combat deployment. JAMA. 2008;300:663-675. doi:10.1001/jama.300.6.663

5. Boscarino JA, Hoffman SN, Pitcavage JM, Urosevich TG. Mental health disorders and treatment seeking among veterans in non-VA facilities: results and implications from the Veterans' Health Study. Military Behav Health. 2015;3:244-254. doi:10.1080/21635 781.2015.1077179

6. Hu Y, Chu X, Urosevich TG, et al. Predictors of Current DSM-5 PTSD Diagnosis and Symptom Severity Among Deployed Veterans: significance of Predisposition, Stress Exposure, and Genetics. Neuropsychiatr Dis Treat. 2020;16:43-54. doi:10.2147/NDT. S228802

7. Boscarino JA, Adams RE, Urosevich TG, et al. Mental Health Impact of Homecoming Experience Among 1730 Formerly Deployed Veterans From the Vietnam War to Current Conflicts: results From the Veterans' Health Study. J Nerv Ment Dis. 2018;206:757-764. doi:10.1097/NMD.0000000000000879

8. Boscarino JA. External-cause mortality after psychologic trauma: the effects of stress exposure and predisposition. Compr Psychiatry. 2006;47:503-514. doi:10.1016/j.comppsych.2006.02.006

9. Boscarino JA, Kirchner HL, Hoffman SN, Erlich PM. Predicting PTSD using the New York Risk Score with genotype data: potential clinical and research opportunities. Neuropsychiatr Dis Treat. 2013;9:517-527. doi:10.2147/NDT.S42422

10. Ursano RJ, Naifeh JA, Kessler RC, et al. Nonfatal suicidal behaviors in the administrative records of activated US Army National Guard and Army Reserve Soldiers, 2004-2009. Psychiatry. 2018;81:173-192. doi:10.1080/00332747.2018.1460716

11. Ursano RJ, Kessler RC, Heeringa SG, et al. Nonfatal suicidal behaviors in US Army administrative records, 2004-2009: results from the Army Study to Assess Risk and Resilience in Servicemembers (Army STARRS). Psychiatry. 2015;78:1-21. doi:10.1080/ 00332747.2015.1006512

12. Nock MK, Stein MB, Heeringa SG, et al. Prevalence and correlates of suicidal behavior among soldiers: results from the Army Study to Assess Risk and Resilience in Servicemembers (Army STARRS). JAMA Psychiatry. 2014;71:514-522. doi:10.1001/jamapsych iatry.2014.30

13. Bossarte RM, Knox KL, Piegari R, Altieri J, Kemp J, Katz IR. Prevalence and characteristics of suicide ideation and attempts among active military and veteran participants in a national health survey. Am J Public Health. 2012;102:S38-S40. doi:10.2105/ AJPH.2011.300487

14. Miller M, Barber C, Young M, Azrael D, Mukamal K, Lawler E. Veterans and suicide: a reexamination of the national death index linked national health interview survey. Am J Public Health. 2012;102:S154-S159. doi:10.2105/AJPH.2011.300409

15. Kaplan MS, Huguet N, McFarland BH, Newsom JT. Suicide among male veterans: a prospective population-based study. J Epidemiol Community Health. 2007;61:619-624. doi:10.1136/jech.2006.054346

16. Schoenbaum M, Kessler RC, Gilman SE, et al. Predictors of suicide and accident death in the Army Study to Assess Risk and Resilience in Servicemembers (Army STARRS): results from the Army Study to Assess Risk and Resilience in Servicemembers (Army STARRS). JAMA Psychiatry. 2014;71:493-503. doi:10.1001/jamapsych iatry.2013.4417
17. Zhang L, Hu XZ, Benedek DM, et al. Genetic predictor of current suicidal ideation in US service members deployed to Iraq and Afghanistan. J Psychiatr Res. 2019;113:65-71. doi:10.1016/j. jpsychires.2019.03.007

18. Kimbrel NA, Garrett ME, Dennis MF, et al. A genome-wide association study of suicide attempts and suicidal ideation in U.S. military veterans. Psychiatry Res. 2018;269:64-69. doi:10.1016/j. psychres.2018.07.017

19. Warrener CD, Valentin EM, Gallin C, et al. The role of oxytocin signaling in depression and suicidality in returning war veterans. Psychoneuroendocrinology. 2021;126:105085. doi:10.1016/j. psyneuen.2020.105085

20. Baldessarini RJ, Hennen J. Genetics of suicide: an overview. Harv Rev Psychiatry. 2004;12:1-13. doi:10.1080/714858479

21. Li J, Yoshikawa A, Meltzer HY. Replication of rs300774, a genetic biomarker near ACP1, associated with suicide attempts in patients with schizophrenia: relation to brain cholesterol biosynthesis. $J$ Psychiatr Res. 2017;94:54-61. doi:10.1016/j.jpsychires.20 17.06.005

22. Boscarino JA, Erlich PM, Hoffman SN, Zhang X. Higher FKBP5, COMT, CHRNA5, and CRHR1 allele burdens are associated with PTSD and interact with trauma exposure: implications for neuropsychiatric research and treatment. Neuropsychiatr Dis Treat. 2012;8:131-139. doi:10.2147/NDT.S29508

23. Boscarino JA, Erlich PM, Hoffman SN, Rukstalis M. Association of FKBP5, COMT and CHRNA5 polymorphisms with PTSD among outpatients at risk for PTSD. Psychiatry Res. 2011;188:173-174. doi:10.1016/j.psychres.2011.03.002

24. Boscarino JJ, Figley CR, Adams RE, Urosevich TG, Kirchner HL, Boscarino JA. Mental health status in veterans residing in rural versus non-rural areas: results from the Veterans' Health Study. Mil Med Res. 2020;7:44. doi:10.1186/s40779-020-00272-6

25. Boscarino JA, Adams RE, Urosevich TG, et al. Guard/Reserve service members and mental health outcomes following deployment: results from the Veterans' Health Study. Gen Hosp Psychiatry. 2020;62:102-103. doi:10.1016/j.genhosppsych.2019.03.002

26. DeBeer BB, Meyer EC, Kimbrel NA, Kittel JA, Gulliver SB, Morissette SB. Psychological inflexibility predicts of suicidal ideation over time in veterans of the conflicts in Iraq and Afghanistan. Suicide LifeThreatening Behav. 2018;48:627-641. doi:10.1111/ sltb. 12388

27. Bryan CJ, Hernandez AM. The functions of social support as protective factors for suicidal ideation in a sample of Air Force personnel. Suicide LifeThreatening Behav. 2013;43:562-573.

28. MacDermott D. Psychological hardiness and meaning making as protection against sequelae in veterans of the wars in Iraq and Afghanistan. Int J Emerg Ment Health. 2010;12(3):199-206.

29. Allan NP, Ashrafioun L, Kolnogorova K, Raines AM, Hoge CW, Stecker T. Interactive effects of PTSD and substance use on suicidal ideation and behavior in military personnel: increased risk from marijuana use. Depress Anxiety. 2019;36:1072-1079. doi:10.1002/da.22954

30. Maiocco G, Vance B, Dichiacchio T. Readiness of Non-Veteran Health Administration Advanced Practice Registered Nurses to Care for Those Who Have Served: a Multimethod Descriptive Study. Policy Polit Nurs Pract. 2020;21:82-94. doi:10.1177/ 1527154420923749

31. Stroupe KT, Martinez R, Hogan TP, et al. Experiences with the Veterans' Choice Program. J Gen Intern Med. 2019;34:2141-2149. doi:10.1007/s11606-019-05224-y

32. McGraw K, Adler J, Andersen SB, et al. Mental health care for service members and their families across the globe. Mil Med. 2019;184:418-425. doi:10.1093/milmed/usy324

33. Si YJ, Guo QW, Chen X, Yang M, Lin J, Fang DZ. Increased TG/ HDL-C in female G allele carriers of rs 1061622 at gene of tumour necrosis factor receptor 2 with suicidal ideation. Eur J Clin Invest. 2020;50:e13322. doi:10.1111/eci.13322 
34. Boscarino JA. Post-traumatic stress and associated disorders among Vietnam veterans: the significance of combat exposure and social support. J Trauma Stress. 1995;8:317-336. doi:10.1002/ jts.2490080211

35. Nash WP, Litz BT. Moral injury: a mechanism for war-related psychological trauma in military family members. Clin Child Fam Psychol Rev. 2013;16:365-375. doi:10.1007/s10567-013-0146-y

36. American Psychiatric Association. Diagnostic and Statistical Manual of Mental Disorders. 5th. American Psychiatric Association; 2013.

37. Gutkind S, Fink DS, Shmulewitz D, Stohl M, Hasin D. Psychosocial and health problems associated with alcohol use disorder and cannabis use disorder in U.S. Adults. Drug Alcohol Depend. 2021;229:109137. doi:10.1016/j.drugalcdep.2021.109137

38. Felitti VJ, Anda RF, Nordenberg D, et al. Relationship of childhood abuse and household dysfunction to many of the leading causes of death in adults: the Adverse Childhood Experiences (ACE) Study. Am J Prev Med. 1998;14:245-258. doi:10.1016/S0749-3797(98)00017-8

39. Chapman DP, Whitfield CL, Felitti VJ, Dube SR, Edwards VJ, Anda RF. Adverse childhood experiences and the risk of depressive disorders in adulthood. $J$ Affect Disord. 2004;82:217-225. doi:10.1016/j.jad.2003.12.013

40. Adams RE, Urosevich TG, Hoffman SN, et al. Social and psychological risk and protective factors for veteran well-being: the role of veteran identity and its implications for intervention. Military Behav Health. 2019;7:304-314. doi:10.1080/21635781.2019.1580642

41. Adams RE, Boscarino JA. Volunteerism and well-being in the context of the World Trade Center terrorist attacks. Int J Emerg Ment Health. 2015;17:274-282. doi:10.4172/1522-4821.1000158

42. Adams RE, Boscarino JA. Stress and well-being in the aftermath of the World Trade Center attack: the continuing effects of a communitywide disaster. J Community Psychol. 2005;33:175-190. doi:10.1002/jcop. 20030

43. Lent MR, Hoffman SN, Kirchner HL, Urosevich TG, Boscarino JJ, Boscarino JA. Attitudes about future genetic testing for posttraumatic stress disorder and addiction among community-based veterans. Front Psychiatry. 2017;8:76. doi:10.3389/fpsyt.2017.00076

44. Strachan T, Read A. Human Molecular Genetics. 4th ed. New York, NY: Garland Science; 2011.

45. Borges G, Nock MK, Haro Abad JM, et al. Twelve-month prevalence of and risk factors for suicide attempts in the World Health Organization World Mental Health Surveys. J Clin Psychiatry. 2010;71:1617-1628. doi:10.4088/JCP.08m04967blu

46. Kessler RC, Abelson J, Demler O, et al. Clinical calibration of DSM-IV diagnoses in the World Mental Health (WMH) version of the World Health Organization (WHO) Composite International Diagnostic Interview (WMH-CIDI). Int $J$ Methods Psychiatr Res. 2004;13:122-139. doi:10.1002/mpr.169

47. Kessler RC, Üstün TB. The world mental health (WMH) survey initiative version of the World Health Organization (WHO) Composite International Diagnostic Interview (CIDI). Int J Methods Psychiatr Res. 2004;13:93-121. doi:10.1002/mpr.168

48. Borges G, Walters EE, Kessler RC. Associations of substance use, abuse, and dependence with subsequent suicidal behavior. Am J Epidemiol. 2000;151:781-789. doi:10.1093/oxfordjournals.aje.a010278

49. Bruffaerts R, Kessler RC, Demyttenaere K, Bonnewyn A, Nock MK. Examination of the population attributable risk of different risk factor domains for suicidal thoughts and behaviors. $J$ Affect Disord. 2015;187:66-72. doi:10.1016/j.jad.2015.07.042

50. Adams RE, Urosevich TG, Hoffman SN, et al. Social support, helpseeking, and mental health outcomes among veterans in non-VA facilities: results from the Veterans' Health Study. Military Behav Health. 2017;5:393-405. doi:10.1080/21635781.2017.1333067

51. Bovin MJ, Marx BP, Weathers FW, et al. Psychometric properties of the PTSD checklist for Diagnostic and Statistical Manual of Mental Disorders, fifth edition (PCL-5) in veterans. Psychol Assess. 2016;28:1379. doi:10.1037/pas0000254
52. Blevins CA, Weathers FW, Davis MT, Witte TK, Domino JL. The posttraumatic stress disorder checklist for DSM-5 (PCL-5): development and initial psychometric evaluation. $J$ Trauma Stress. 2015;28:489-498. doi:10.1002/jts.22059

53. Wortmann JH, Jordan AH, Weathers FW, et al. Psychometric analysis of the PTSD Checklist-5 (PCL-5) among treatment-seeking military service members. Psychol Assess. 2016;28:1392. doi:10.1037/pas0000260

54. Cox KS, Resnick HS, Kilpatrick DG. Prevalence and correlates of posttrauma distorted beliefs: evaluating DSM-5 PTSD expanded cognitive symptoms in a national sample. J Trauma Stress. 2014;27:299-306. doi:10.1002/jts.21925

55. First MB. Structured clinical interview for DSM-IV axis I disorders. Biometrics Res Dep. 1997;63:89.

56. Spitzer RL, Williams JB, Gibbon M, First MB. The structured clinical interview for DSM-III-R (SCID): i: history, rationale, and description. Arch Gen Psychiatry. 1992;49:624-629. doi:10.1001/ archpsyc.1992.01820080032005

57. Resnick HS, Kilpatrick DG, Dansky BS, Saunders BE, Best CL. Prevalence of civilian trauma and posttraumatic stress disorder in a representative national sample of women. J Consult Clin Psychol. 1993;61:984. doi:10.1037/0022-006X.61.6.984

58. Kilpatrick DG, Ruggiero KJ, Acierno R, Saunders BE, Resnick HS, Best CL. Violence and risk of PTSD, major depression, substance abuse/ dependence, and comorbidity: results from the National Survey of Adolescents. J Consult Clin Psychol. 2003;71:692. doi:10.1037/0022006X.71.4.692

59. Galea S, Ahern J, Resnick H, et al. Psychological sequelae of the September 11 terrorist attacks in New York City. $N$ Engl J Med. 2002;346:982-987. doi:10.1056/NEJMsa013404

60. Boscarino JA, Galea S, Adams RE, Ahern J, Resnick H, Vlahov D. Mental health service and medication use in New York City after the September 11, 2001, terrorist attack. Psychiatric Services. 2004;55:274-283. doi:10.1176/appi.ps.55.3.274

61. Stouffer S, Lumsdaine A, Lumsdaine M, et al. The American Soldier: Combat and Its Aftermath. Vol. II. New York, NY: John Wiley \& Sons; 1949.

62. Centers for Disease Control. Health status of Vietnam veterans. I. Psychosocial characteristics. The Centers for Disease Control Vietnam Experience Study. JAMA. 1988;259:2701-2707. doi:10.1001/jama.1988.03720180027028

63. Boscarino JA, Forsberg CW, Goldberg J. A twin study of the association between PTSD symptoms and rheumatoid arthritis. Psychosom Med. 2010;72:481-486. doi:10.1097/PSY.0b013e3181d9a80c

64. McLeod DS, Koenen KC, Meyer JM, et al. Genetic and environmental influences on the relationship among combat exposure, posttraumatic stress disorder symptoms, and alcohol use. J Trauma Stress. 2001;14:259-275. doi:10.1023/A:1011157800050

65. Boscarino JA, Adams RE, Figley CR. Mental health service use 1-year after the World Trade Center disaster: implications for mental health care. Gen Hosp Psychiatry. 2004;26:346-358. doi:10.1016/j. genhosppsych.2004.05.001

66. Boscarino JA, Adams RE, Figley CR. Worker productivity and outpatient service use after the September 11th attacks: results from the New York City terrorism outcome study. Am J Ind Med. 2006;49:670-682. doi:10.1002/ajim.20340

67. Vlahov D, Galea S, Resnick H, et al. Increased use of cigarettes, alcohol, and marijuana among Manhattan, New York, residents after the September 11th terrorist attacks. Am J Epidemiol. 2002;155:988-996. doi:10.1093/aje/155.11.988

68. Adams RE, Boscarino JA, Galea S. Social and psychological resources and health outcomes after the World Trade Center disaster. Soc Sci Med. 2006;62:176-188. doi:10.1016/j.socscimed.2005.05.008

69. Campbell-Sills L, Stein MB. Psychometric analysis and refinement of the Connor-Davidson Resilience Scale (CD-RISC): validation of a 10-item measure of resilience. J Trauma Stress. 2007;20:1019-1028. doi: $10.1002 /$ jts. 20271 
70. Boscarino JA, Adams RE. PTSD onset and course following the World Trade Center disaster: findings and implications for future research. Soc Psychiatry Psychiatr Epidemiol. 2009;44:887-898. doi:10.1007/s00127-009-0011-y

71. Tsuang MT, Tohen M, Jones P, eds. Textbook of Psychiatric Epidemiology. 3rd ed. Hoboken, NJ: John Wiley \& Sons; 2011.

72. Lambert SA, Abraham G, Inouye M. Towards clinical utility of polygenic risk scores. Hum Mol Genet. 2019;28:R133-R142. doi: $10.1093 / \mathrm{hmg} / \mathrm{ddz} 187$

73. Lowe SR, Meyers JL, Galea S, et al. RORA and posttraumatic stress trajectories: main effects and interactions with childhood physical abuse history. Brain Behav. 2015;5:e00323. doi:10.1002/brb3.323

74. Binder EB, Bradley RG, Liu W, et al. Association of FKBP5 polymorphisms and childhood abuse with risk of posttraumatic stress disorder symptoms in adults. JAMA. 2008;299:1291-1305. doi:10.1001/jama.299.11.1291

75. Criado-Marrero M, Rein T, Binder EB, Porter JT. Hsp90 and FKBP51: complex regulators of psychiatric diseases. Philosophical Transactions of the Royal Society of London - Series B: Biological Sciences. Philosophical Trans Royal Soc B. 2018;1;373.

76. Spitz MR, Amos CI, Dong Q, Lin J, Wu X. The CHRNA5-A3 region on chromosome $15 \mathrm{q} 24-25.1$ is a risk factor both for nicotine dependence and for lung cancer. JNCI. 2008;100:1552-1556. doi:10.1093/ jnci/djn363

77. Erlich PM, Hoffman SN, Rukstalis M, et al. Nicotinic acetylcholine receptor genes on chromosome $15 \mathrm{q} 25.1$ are associated with nicotine and opioid dependence severity. Hum Genet. 2010;128:491-499. doi:10.1007/s00439-010-0876-6

78. Gillespie CF, Phifer J, Bradley B, Ressler KJ. Risk and resilience: genetic and environmental influences on development of the stress response. Depress Anxiety. 2009;26:984-992. doi:10.1002/da.20605

79. Boscarino JA, Hoffman SN, Urosevich TG, et al. Genetic Risk Factors for Suicide among Community-based Veterans. Presented at Annual Meeting of the Health Care Systems Network Virtual Conference, May 11-12, 2021.

80. Boscarino JA, Figley CR. Understanding the neurobiology of fear conditioning and emergence of posttraumatic stress disorder psychobiology: commentary on Blanchard et al. J Nerv Ment Dis. 2012;200:740-744. doi:10.1097/NMD.0b013e318266b5ea

81. Hosmer DW, Lemeshow S, Cook E. Applied Logistic Regression. 2nd ed. NY: John Wiley \& Sons; 2000.

82. Adams RE, Boscarino JA. Predictors of PTSD and delayed PTSD after disaster: the impact of exposure and psychosocial resources. J Nerv Ment Dis. 2006;194:485-493. doi:10.1097/01. nmd.0000228503.95503.e9

83. Hulley S, Cummings S, Browner W, Grady D, Newman T. Designing Clinical Research. Philadelphia, Baltimore, New York, London, Buenos Aires, Hong Kong: Lippincott Williams \& Wilkins; 2013.

84. Hynes DM, Koelling K, Stroupe K, et al. Veterans' access to and use of Medicare and Veterans Affairs health care. Med Care;2007. 214-223. doi:10.1097/01.mlr.0000244657.90074.b7

85. Shen Y, Hendricks A, Zhang S, Kazis LE. VHA enrollees' health care coverage and use of care. Med Care Res Rev. 2003;60:253-267. doi: $10.1177 / 1077558703060002007$
86. Ritchie EC, Llorente MD. Veteran Psychiatry in the US: Optimizing Clinical Outcomes. Springer; 2019.

87. Dursa EK, Barth SK, Bossarte RM, Schneiderman AI. Demographic, Military, and Health Characteristics of VA Health Care Users and Nonusers Who Served in or During Operation Enduring Freedom or Operation Iraqi Freedom, 2009-2011. Public Health Rep. 2016;131:839-843. doi:10.1177/0033354916676279

88. Boscarino JA, Sitarik A, Gordon SC, et al. Risk factors for hepatitis $\mathrm{C}$ infection among Vietnam era veterans versus nonveterans: results from the Chronic Hepatitis Cohort Study (CHeCS). J Community Health. 2014;39:914-921. doi:10.1007/s10900-014-9863-5

89. Bolton EE, Litz BT, Glenn DM, Orsillo S, Roemer L. The impact of homecoming reception on the adaptation of peacekeepers following deployment. Mil Psychol. 2002;14:241-251. doi:10.1207/ S15327876MP1403_4

90. Urosevich TG, Boscarino JJ, Hoffman SN, et al. Visual dysfunction and associated co-morbidities as predictors of mild traumatic brain injury seen among veterans in non-VA facilities: implications for clinical practice. Mil Med. 2018;183:e564-e570. doi:10.1093/ milmed/usy102

91. Boscarino J. Vietnam veterans, postwar experiences and health outcomes. In: FInk G, editor. Encyclopedia of Stress. Elsevier; 2007:830-838.

92. Boscarino JA, Larson S, Ladd I, Hill E, Paolucci SJ. Mental health experiences and needs among primary care providers treating $\mathrm{OEF} /$ OIF veterans: preliminary findings from the Geisinger Veterans Initiative. Int J Emerg Ment Health. 2010;12:161.

93. Bookwalter DB, Roenfeldt KA, LeardMann CA, Kong SY, Riddle MS, Rull RP. Posttraumatic stress disorder and risk of selected autoimmune diseases among US military personnel. BMC Psychiatry. 2020;20:2432. doi:10.1186/s12888-020-2432-9

94. Gaziano JM, Concato J, Brophy M, et al. Million Veteran Program: a mega-biobank to study genetic influences on health and disease. $J \quad$ Clin Epidemiol. 2016;70:214-223. doi:10.1016/j.jclinepi.20 15.09 .016

95. Laliberte V, Giguere CE, Potvin S, Lesage A. Signature Consortium. Berkson's bias in biobank sampling in a specialised mental health care setting: a comparative cross-sectional study. BMJ Open. 2020;10:e035088. doi:10.1136/bmjopen-2019-035088

96. White MC, Babcock F, Hayes NS, et al. The history and use of cancer registry data by public health cancer control programs in the United States. Cancer. 2017;123:4969-4976. doi:10.1002/cncr.30905

97. Boscarino JA, Lu M, Moorman AC, et al. Predictors of poor mental and physical health status among patients with chronic hepatitis C infection: the Chronic Hepatitis Cohort Study (CHeCS). Hepatology. 2015;61:802-811. doi:10.1002/hep.27422

98. Daida YG, Boscarino JA, Moorman AC, et al. Mental and physical health status among chronic hepatitis B patients. Qual Life Res. 2020;29:1567-1577. doi:10.1007/s11136-020-02416-6

99. Boscarino JA, Kirchner HL, Hoffman SN, Sartorius J, Adams RE, Figley CR. Predicting Future PTSD using a Modified New York Risk Score: implications for Patient Screening and Management. Minerva Psichiatr. 2012;53:47-59.
Pharmacogenomics and Personalized Medicine

\section{Publish your work in this journal}

Pharmacogenomics and Personalized Medicine is an international, peer-reviewed, open access journal characterizing the influence of genotype on pharmacology leading to the development of personalized treatment programs and individualized drug selection for improved safety, efficacy and sustainability. This journal is indexed on the American Chemical Society's Chemical Abstracts Service (CAS). The manuscript management system is completely online and includes a very quick and fair peer-review system, which is all easy to use. Visit http://www.dovepress.com/testimonials.php to read real quotes from published authors. 